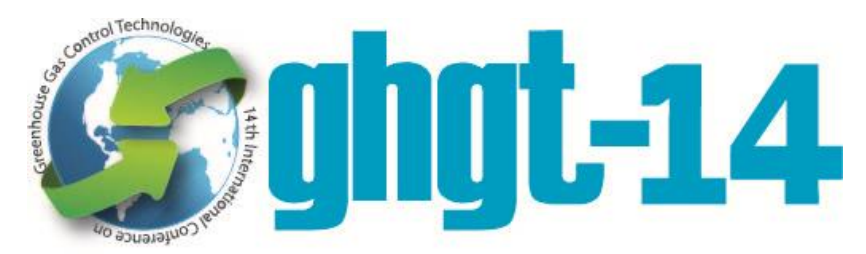

14th International Conference on Greenhouse Gas Control Technologies, GHGT-14 $21^{\text {st }}-25^{\text {th }}$ October 2018, Melbourne, Australia

\title{
Time-lapse VSP with permanent seismic sources and distributed acoustic sensors: CO2CRC Stage 3 equipment trials
}

\author{
Julia Correa ${ }^{\mathrm{a}, \mathrm{b}, \mathrm{c} *}$, Konstantin Tertyshnikov ${ }^{\mathrm{a}, \mathrm{b}}$, Todd Wood $^{\mathrm{c}}$, Sinem Yavuz ${ }^{\mathrm{a}, \mathrm{b}}$, Barry \\ Freifeld $^{\mathrm{c}}$, and Roman Pevzner ${ }^{\mathrm{a}, \mathrm{b}}$ \\ ${ }^{a}$ Curtin University, 26 Dick Perry Ave, Kensignton 6152, Australia \\ ${ }^{b}$ CO2CRC, 11-15 Argyle Place South, Carlton 3053, Australia \\ ${ }^{c}$ Lawrence Berkeley National Laboratory, 1 Cyclotron Road, Berkeley 94720, USA
}

\begin{abstract}
Abs tract
Effective monitoring of the carbon dioxide storage is es sential to ens ure safe containment of the $\mathrm{CO}_{2}$ plume in the reservoir. Currently geophysical monitoring u sually involves a combination of various s eismic surveys acquired using a large array of seis mic receivers and moveable sources to image the emplaced gas plume. Deployment of equipment for such surveys usually takes a long time which becomes expensive. At the CO2CRC Otway Research Facility we are exploring the use of distributed acoustic sensing (DAS) combined with permanent surface orbital vibrators (SOVs) in order to build a permanent seismic monitoring array that is able to image the development of the plume in real time. In this study, we acquire a series of VSP trials to test performance of DAS in combination of SOV sources. The objective was to test different fibre types and different sweep parameters. The results of the field trials show that DAS/SOV configuration present good quality VSP datasets, imaging beyond the injection interval when using a more powerful motor with sweeps from 0 to $80 \mathrm{~Hz}$.
\end{abstract}

Keywords: fibre-optics sensing; distributed acoustic sensing; reservoir monitoring; vertical seismic profile.

\section{Introduction}

In carbon geosequestration projects there is an essentialneed for effective monitoring of the carbon dioxide storage over decades to en sure safe containment of the $\mathrm{CO}_{2}$ plume in the reservoir. Geophysical monitoring of the reservoir usually involves a combination of various seismic surveys acquired using a large array of seismic receivers and moveable sources to image the emplaced gas plume. Deployment of equipment for such surveys usually takes a long time. The standard geophysical approach is to temporarily deploy seismic receivers, such as geophones; theinherent effort requires significant labour and results in significant equipment maintenance costs. Also, conventional onshore seis mic surveys depend on accessing large swathes of terrain with heavy hydraulically operated vibroseis trucks or auger rigs (for dynamite surveys). The complexity of such surveys makes the conventional approach costly and, at times, unviable for carbon geosequestration applications. Furthermore, errors in repeatability of source and receiver locations can limit the effectiveness of the approach. Permanent reservoir monitoring seeks to overcome the limitations

\footnotetext{
* Corresponding author. Tel.: +61 892663408.

E-mail address: julia.correa@postgrad.curtin.edu.au
} 
of the conventional approach by fixing either the seismic receivers, sources or both. At the CO2CRC Otway Res earch Facility, we developed a permanent monitoring array consis ting of permanently installed dis tributed acoustic sensing (DAS) in wells, combined with surface orbital vibrators (SOVs) also installed permanently, to create a continuous seis mic monitoring array and track the injected $\mathrm{CO}_{2}$ plume.

DAS senses the seismic signal by simply using stand ard fibre-optic cables. A surface-based interrogator unit sends a series of light pulses through a fibre-optic cable. By analy zing the differences of the backs cattered light, DAS can measure the changes of strain along the fibre length [1]. For permanent monitoring applications, DAS is becoming significantly more economically viable compared to conventional seismic sensors due to the inherent robustness of the fibre-optic cable and affordability.

SOV sources can be used in monitoring surveys to reduce the cost and land impact compared to vibroseis sources. The seis mic signal is generated by rotating eccentric weights. The SOV sources produce both a vertical and horizontal shear force [2]. The combination of observation wells instrumented with DAS and permanent sources can offer the cost-effective real time monitoring sufficient to image the $\mathrm{CO}_{2}$ plume and as sure res ervoir integrity. The surface trenched fibre-optics DAS and the SOV sources were als o evaluated at Otway, showing that they could potentially be used as an economical configuration in time-lapse surveys [3].

The CO2CRC Otway Research Facility is Australia's first demons tration of deep geological storage of carbon dioxide. The next stage of the project (Stage 3) aims to build a multi-well monitoring approach [4]. Several wells will be drilled on site and will be instrumented with fibre-optic cables along their length. In January 2017, a new well (CRC-3 well) was drilled on site as part of the Stage 3 program. A set of standard straight single-mode fibres and enhanced sensitivity fibres (en gineered to increase light backscatter) were installed cemented behind the well casing. Field trials show that VSP data acquired with DAS on CRC-3 well present high signal to noise ratio and has the potential to image the injection interval [5].

We present the analy sis of a series of seis mic acquisitions performed at the CRC-3 well us ing DAS receivers and SOV sources. In this experiment, we acquire DAS VSP using both the standard fibre-optic cable and backscatter enhanced fibre. The VSP survey is acquired with two SOV sources installed at offs ets of approximately 380 and 630 meters. We als o tested different s weep designs on the SOVs and compare their performances.

\section{Data acquisition}

Two field trials were conducted at the Otway Project site. The first field trial was conducted in May 2017. We acquired a series of VSP datasets in CRC-3 well, using a standard straight fibre-optic cable (referred as DASv2 in this paper) and an enhanced sensitivity cable (referred as DASv3). The trial was performed with two SOV sources. SOV1 was located at approximately $630 \mathrm{~m}$ from the well, and SOV2 was located approximately $380 \mathrm{~m}$ from the well. The aim of this trial was to test the performance of different fibre types in combination with the SOV sources. In this trial, we used sweeps from 0 to $80 \mathrm{~Hz}$ (Table 1).

The second field trial was conducted in November 2017. A standard single-mode fibre was used to acquire DAS data. In this field trial, different SOV source configurations and sweeps were tested. The force of the sweep on SOV sources is proportional to the frequency squared. This means that the force on the low frequencies of the sweep is much lower than the force on the high frequencies. To overcome this is sue, the SOV s ources were tested using a larger motor (10 T-f), which will consequently increase the force. However, on large motors, the SOV s weeps should only go up to approximately $80 \mathrm{~Hz}$, as this is close to the limiting speed of the motor bearings. To overcome the lack of high frequencies in the data, we tested sweeps using small motors $(2.5 \mathrm{~T}-\mathrm{f})$, varying frequencies to up to $160 \mathrm{~Hz}$ (Table 2).

Table 1: Acquisition parameters for May 2017 field trial.

\begin{tabular}{c|c}
\hline \multicolumn{2}{c}{ May Test } \\
\hline SOV 1 & SOV 2 \\
\hline Large motors, $0-80 \mathrm{~Hz}$ & Large motors, $0-80 \mathrm{~Hz}$ \\
\hline
\end{tabular}


Table 2: Acquisition parameters for November 2017 field trial.

\begin{tabular}{c|c}
\hline \multicolumn{2}{c}{ November Test } \\
\hline \multicolumn{1}{c}{ SOV 1 } & \multicolumn{1}{c}{ SOV 2 } \\
\hline Large motors, $0-80 \mathrm{~Hz}$ & Large motors, $0-80 \mathrm{~Hz}$ \\
Small motors, $0-120 \mathrm{~Hz} ; 50 \%$ peak force & Small motors, $0-120 \mathrm{~Hz} ; 50 \%$ peak force \\
& Small motors, $0-160 \mathrm{~Hz} ; 50 \%$ peak force \\
\hline
\end{tabular}

\section{Data analysis}

We analyse the data quality of the VSP acquired by DAS with both SOV sources from the first field trial (May test). To compare both DAS systems, a band pass filter was applied on all shots to se lect frequencies from 5 to 140 $\mathrm{Hz}$ (filter had 5 to $10 \mathrm{~Hz}$ taper, and 80 to $140 \mathrm{Hztaper}$ ). Each dis play shows vertical stacks of 14 repeated shots. Figure 1 ( $a$ and $b$ ) shows the VSP data acquired for SOV1, at $630 \mathrm{~m}$ distance from the well. The VSP data acquired with the enhanced cable (a and c) presents less random noise when compared to the standard single-mode fibre (b and d), probably due to the stronger signal amplitude in relation to noise. The enhanced fibre presents a set of traces covering $70 \mathrm{~m}$ in length, at depth of approximately $1390 \mathrm{~m}$ that did not exhibit enhanced Rayleigh scattering due to a manufacturing error. The standard fibre presents higher level of randomnoise compared to the enhanced fibre. It also detects clear P-wave reflections along the entire length of the fibre. Figure 1 ( $\mathrm{c}$ and d) shows the data acquired with SOV2, at 320 m distance from the well. Both fibres present clear reflections, with the standard fibre showing stronger randomnoise. At both shot positions, DAS acquired not only P-wave reflections, but also PS-waves and S-waves.

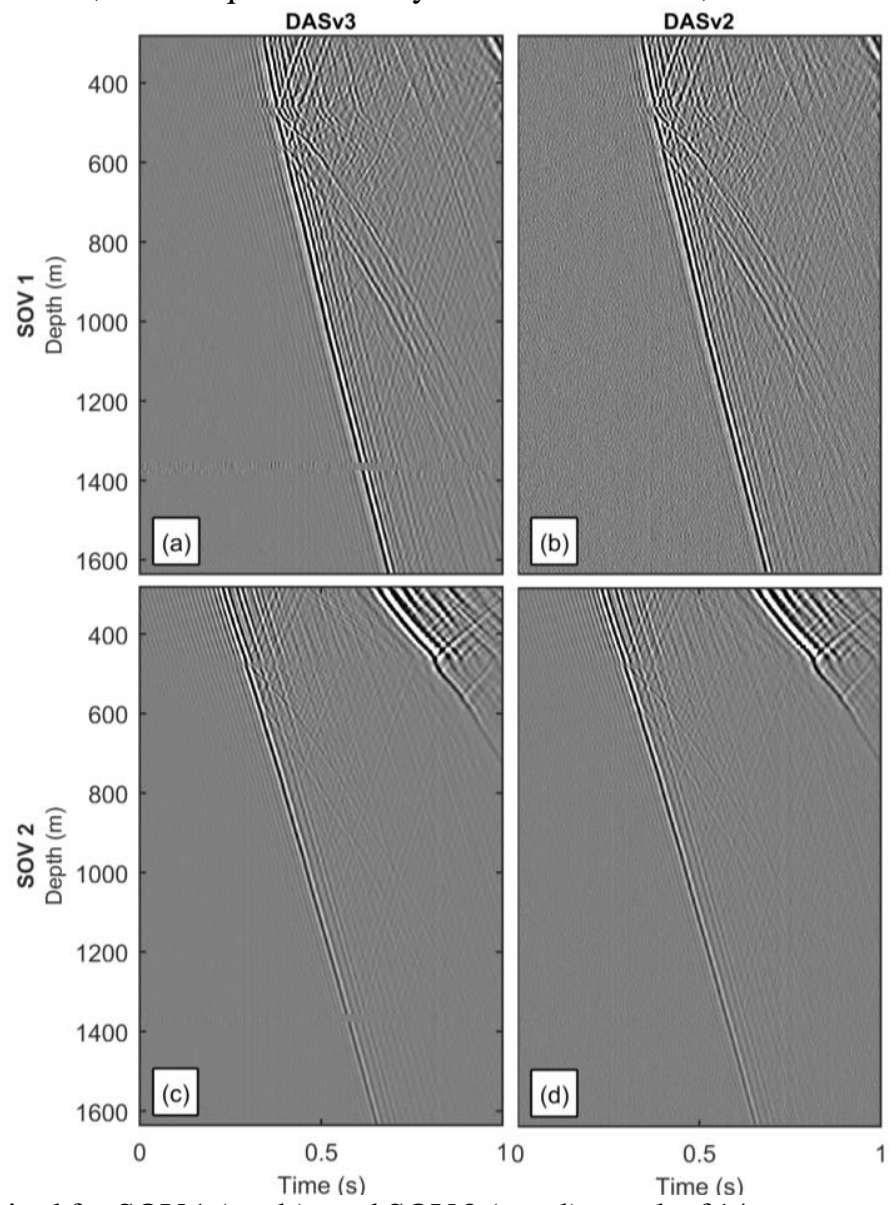

Figure 1: VSP records acquired for SOV $1(\mathrm{a}-\mathrm{b})$, and SOV $2(\mathrm{c}-\mathrm{d})$, stack of 14 sweeps. 
For the second field trial (November test), we als o stack a number of repeated s weeps to increase the signal-tonoise ratio. DAS datasets with large motors were stacked with 10 repeated sweeps, with small motors of maximum sweep frequency of $120 \mathrm{~Hz}$ - 16 repeated sweeps were stacked, and for s mall motors of maximum sweep frequency of $160 \mathrm{~Hz}-5$ repeated s weeps were stacked. Wavefield separation was applied to each dataset to obtain the upgoing P-wave reflection, where they were then NMO corrected using a one-dimensional velocity model, through the VSP to CDP transform. Figure 2 shows the results from the second field trial after VSP-CDP transform. The 2D line produced for each source is dis played side by side; the well location is where both lines meet (well path is displayed in red). The data acquired in all tests were able to record reflections, at least until $1000 \mathrm{~m}$ depth. The large motors using sweeps from 0 to $80 \mathrm{~Hz}$ present by far the best performance, given it presents higher signal to noise ratio [6] and it images deeper reflectors. The data with the large motors was able to acquire reflection frombey ond $2 \mathrm{~km}$ depth. Note that the reflections on the 2D line for SOV1 match well with the reflections for the 2D line for SOV2 (Figure 2a). Data acquired with s weeps from 0 to $160 \mathrm{~Hz}$ presents higher resolution at shallow depths, however, it was unable to image deep reflectors (Figure2c).
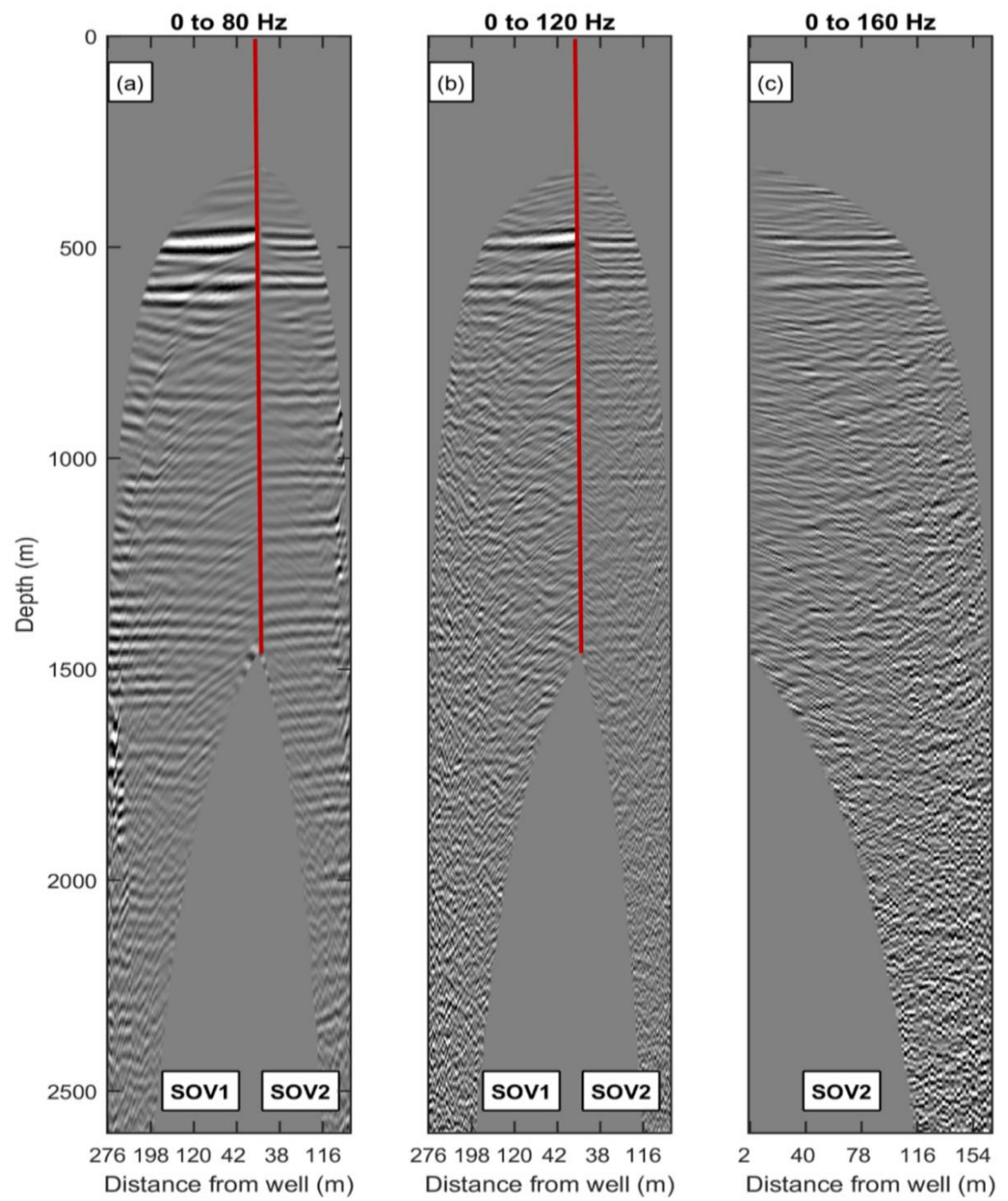

Figure 2: Results of VSP to CDP transformfor test with sweeps from 0 to $80 \mathrm{~Hz}$, large motors (a), from 0 to $120 \mathrm{~Hz}$, small motors (b), and from 0 to $160 \mathrm{~Hz}$, small motors (c). The 2D line corres pondent to SOV1 and SOV2 are dis played side by side. Well path is dis played in red. 


\section{Conclusions}

The results show that a VSPDAS acquired with a cemented cable and SOVs yields high quality datasets, sufficient to image the injected gas plume. We conclude thatDAS combined with SOVs is a cost-effective option for permanent reservoir monitoring.

The first field trial as sessed the performance of DAS/SOV using a standard fibre-optic cable and an "enhanced" sensitivity cable. The second field trial aimed to test for optimal performance of the source by acquiring a range of s weeps with large and smaller motors, from maximum frequency of 80 to $160 \mathrm{~Hz}$.

At both locations DAS was able to acquire P-wave up-going reflections. DAS acquired with the enhanced fibre shows lower levels of randomnoise compare to the stand ard fibre. Nevertheless, the standard fibre was able to record the same P-wave reflections (while using larger motors).

The large motors provide higher signal levels due to the higher source power than the small motors. Due to the higher frequency content, small motors provide better resolution. Both sweeps from up to $80 \mathrm{~Hz}$ and up to $120 \mathrm{~Hz}$ were able to record reflections from the target depth at $1500 \mathrm{~m}$ at the nearest offset (SOV2).

\section{Acknowledgements}

The Otway Project received CO2CRC funding through its industry members and research partners, the Australian Government under the CCS Flagships Programme, the Victorian State Government, and the Global CCS Institute. The authors wish to acknowledge financial as sistance provided through Australian National Low Emissions Coal Research and Development supported by the Australian Coal As sociation Low Emis sions Technology Limited and the Australian Government through the Clean Energy Initiative. Funding for LBNL was provided through the Carbon Storage Program, U.S. DOE, As sistant Secretary for Fossil Energy, Office of Clean Coal and Carbon Management through the NETL. We are grateful for the as is tance from Silixa Ltd. We als o thank our colleagues from CO2CRC, LBNL, and Curtin University.

\section{References}

[1] Parker T., Shatalin S., Farhadiroushan M. Distributed Acoustic Sensing-a new tool for seismic applications. First Break 2014, 32, no. 2, 6169.

[2] Daley T. M., Cox D. Orbital vibrator seismic source for simultaneous P-and S-wave crosswell acquisition. Geophysics 2001, 66, 1471-1480, http://dx.doi.org/10.1190/1.1487092.

[3] Dou S., Ajo-Franklin J., Daley T., Robertson M., Wood T., Freifeld B., Pevzner R., Correa J., Tertyshnikov K., Urosevic M., Gurevich B. Surface orbital vibrator (SOV) and fiber-optic DAS: Field demonstration of economical, continuous-land seismic time-lapse monitoring from the Australian CO2CRC Otway site. SEG Technical Program Expanded Abstracts 2016: pp. 5552-5556. https://doi.org/10.1190/segam2016-

13974161.1

[4] Charles J., Marshall S., Dance T., Ennis-King J., Glubokovskikh S., Gurevich B., La Force T., Paterson L., Pevzner R., Tenthorey E., Watson M. Validating Subsurface Monitoring as an Alternative Option to Surface M\&V - The CO2CRC's Otway Stage 3 Injection. Energy Procedia 2017, 114, 3374-3384.

[5] Correa J., Egorov A., Tertyshnikov K., Bona A., Pevzner R., Dean T., Freifeld B., Marshall S. Analysis of signal to noise and directivity characteristics of DAS VSP at near and far offsets - A CO2CRC Otway Project data example. The Leading Edge 2017, 36(12), 994a1-994a7. https://doi.org/10.1190/tle36120994a1.1

[6] Correa, J., Freifeld B.M., Pevzner R., Wood T., Tertyshnikov K., Bona A. Continuous DAS VSP monitoring using surface orbital vibrators: field trials for optimal configuration at the CO2CRC Otway Project. EAGE 2018, Expended Abstracts, WS08. 